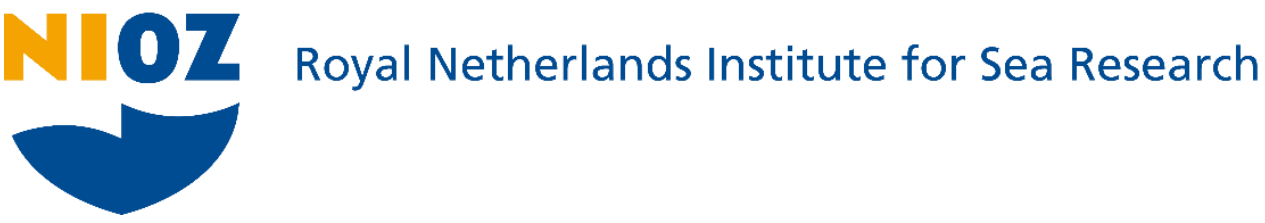

This is a postprint of:

Mathot, K.J. \& Frankenhuis, W.E. (2018). Models of pace-of-life syndromes (POLS): a systematic review. Behavioral Ecology and Sociobiology, 72: 41

Published version: https://doi.org/10.1007/s00265-018-2459-9

Link NIOZ Repository: www.vliz.be/imis?module=ref\&refid=295102

[Article begins on next page]

The NIOZ Repository gives free access to the digital collection of the work of the Royal Netherlands Institute for Sea Research. This archive is managed according to the principles of the Open Access Movement, and the Open Archive Initiative. Each publication should be cited to its original source - please use the reference as presented.

When using parts of, or whole publications in your own work, permission from the author(s) or copyright holder(s) is always needed. 


\section{Models of pace-of-life syndromes (POLS): a systematic review}

2 Kimberley J. Mathot ${ }^{1^{*}}$ and Willem E. Frankenhuis ${ }^{2}$

3

$4 \quad{ }^{1}$ NIOZ Royal Netherlands Institute for Sea Research, Department of Coastal Systems (COS) and Utrecht

5 University, P.O.Box 59, 1790 AB Den Burg, Texel, The Netherlands.

$6 \quad{ }^{2}$ Behavioural Science Institute (BSI), Radboud University Nijmegen, Montessorilaan 3, 6525 HR Nijmegen, The

7 Netherlands.

8 *Author for correspondence, current address: University of Alberta, Department of Biological Sciences,

9 Edmonton, Alberta, Canada, mathot@ualberta.ca, phone: 1-780-248-1234

\section{Acknowledgments}

12 The idea for this paper developed from discussions during a Volkswagon Stiftung Workshop "Towards a

13 General Theory of Pace of Life" [89905]. We thank the workshop organisors, Melanie Dammhahn, Niels

14 Dingemanse, Petri Niëmela, and Denis Réale, for inviting us to participate in this workshop. KJM and WEF

15 were each supported by Veni Fellowships (KJM: 863.14.021, WEF: 016.155.195) from the Netherlands

16 Organisation for Scientific Research (NWO, Nederlandse Organisatie voor Wetenschappelijk Onderzoek) while

17 writing this paper. We thank Melanie Dammhahn, Max Wolf, and Pierre-Olivier Montiglio and one anonymous referee for commenting on a previous version of the manuscript. 


\section{Abstract}

20

Variation in life-history (LH) traits along the fast-slow continuum (referred to as pace-of-life, POL) is thought to result from a trade-off between investments in current versus future reproduction. Originally developed for understanding variation in LH strategies at the among-population level, POL theory has more recently been applied towards understanding variation in LH traits at the within-population level, and further extended to address the covariance of LH traits with additional behavioural and/or physiological traits, referred to as pace-oflife syndromes (POLS). The article by Réale et al. (2010; Philos T Roy Soc B 365:4051-4063), which synthesized several earlier reviews and opinions on among-individual covariation between LH, behavioural, and physiological traits, and subsequent research testing POLS in a variety of species, have collectively been cited several hundreds of times - a trend that continues. These works have interdisciplinary impact, informing research in life history biology, behavioural and developmental biology, and the social sciences. In this paper, we review the existing theoretical POLS models that provide adaptive explanations for covariances between LH traits and additional behavioural and/or physiological traits while assuming a trade-off between current and future reproduction. We find that the set of relevant models is small. Moreover, models show that covariances between life-history traits and behavioural or physiological traits can arise even in the absence of a current-future reproduction trade-off, implying that observing such covariances does not provide a strong indication regarding the process generating POLS. We discuss lessons learned from existing models of POLS, highlight key gaps in the modelling literature, and provide guidelines for better integration between theory and data.

Keywords: animal personality, consistent among-individual differences, life history trade-offs, physiology, trait covariance 
40 "Science walks forward on two feet, namely theory and experiment ... Sometimes it is one foot that is put

41 forward first, sometimes the other, but continuous progress is only made by the use of both."

42 - Robert A. Millikan, Nobel Lecture 1924

\section{Introduction}

Life-history (LH) traits often vary along a fast-slow continuum, with a fast pace-of-life (POL) characterized by fast development, early age at first reproduction, and low survival, and a slow POL by slow development, delayed reproduction, and high survival (Saether 1988; Stearns 1992; Ricklefs 2000). These patterns of covariation may result from allocation trade-offs (Williams 1966); resources invested in current reproduction cannot be invested in growth, survival, or future reproduction. Ecological conditions can mediate the resolution of this trade-off, resulting in differences in LH traits across populations experiencing different ecological conditions (Stearns 1992). POL theory was later extended to address the coevolution of behavioural and physiological traits with the LH particularities of a species or population (Ricklefs and Wikelski 2002), referred to as pace-of-life syndromes (POLS). For example, organisms evolved towards a slow POL may invest more in traits that increase their probability of surviving long-enough to realize their future reproductive potential (e.g. immunity) (Martin et al. 2006). Similarly, organisms evolved towards a fast POL may accept greater risk while foraging to build assets for immediate reproduction (Stamps 2007).

More recently, Réale et al. (2010) suggested that the POLS concept may provide a useful framework for understanding covariation between $\mathrm{LH}$, behavioural and physiological traits among individuals of the same population. Within-populations, individuals exhibit differences in LH strategies (Biro and Stamps 2008), as well as consistent differences in behavioural (Bell et al. 2009) and physiological traits (Holtmann et al. 2016), and LH, behavioural, and physiological traits often co-vary at the among-individual level (Stamps 2007; Biro and Stamps 2008, 2010; Careau et al. 2008). In their paper, Réale et al. (2010) synthesized these previous bodies of work and developed a series of verbal arguments for how and why LH, behavioural and physiological traits may show particular patterns of covariance at the among-individual, within-population level (see also Belsky et al. 1991; Ellis et al. 2009 for verbal models of POLS in humans; Del Giudice et al. 2015). For example, if aggressiveness facilitates the acquisition or monopolization of resources, it may have coevolved with high growth rates and early reproduction, but at the cost of increased risk of mortality. Similarly, high metabolic rates may be required to support the rapid growth required for early reproduction and high fecundity, but may simultaneously increase mortality through increased production of reactive oxygen species. Since its 
publication, the POLS hypothesis at the within-population level has generated a large amount of empirical research (cited over 300 times, see Dammhahn et al. 2017; Royauté et al. 2017).

In this paper, we provide a systematic review of the formal (i.e. mathematical) theory of POLS. We review existing models that incorporate a trade-off between current and future reproduction while addressing covariation between LH, behaviour, and physiology at the within-population level. We focus on models that incorporate the current-future reproduction trade-off, which features prominently in verbal POLS theory (e.g. Ricklefs and Wikelski 2002; Réale et al. 2010). We acknowledge, however, that other trade-offs may also produce POLS (see section on Equifinality, below).

Our results show that there is in fact little formal theory about POLS, particularly at the among-individual, within-population level, and many empirical tests of POLS have no formal bases for their predictions. We discuss the key assumptions and predictions of existing models, highlighting the mismatch between current empirical tests and model assumptions. Further, we discuss models that predict patterns of covariance between LH, behavioural, and physiological traits via different processes than a current-future reproduction trade-off. Such models are relevant for the evolution of POLS, but are rarely cited in the POLS literature. The mismatch between formal theory and empirical work does not, of course, undermine either; rather, it highlights the need and potential for the development of novel theory addressing the evolution of POLS. Our aim is thus to facilitate better integration of theory and empirical work by highlighting gaps in the current set of models to stimulate the development of further theory and offer guidelines that help in devising tests of extant theory.

\section{Models of POLS at the within-population level}

In reviewing the literature, we followed the Preferred Reporting Items for Systematic Reviews and MetaAnalyses (PRISMA) protocol (Moher et al. 2009). We searched the Web of Science database (search date 08.01.2016) for articles that included the key words "Pace of life" and "Model" or articles that cited Réale et al. (2010). This produced 166 unique references. We read the title and/or abstract for each of these references to assess whether the paper developed a formal model including a life history trait (e.g. age at first reproduction, survival, etc.) and any additional behavioural and/or physiological trait. We considered models that addressed the co-evolution of LH and behavioural and/or physiological traits, as well as the development of POLS over ecological time (e.g. models of phenotypic plasticity). These models tended to address among- and withinindividual covariation respectively. We selected papers that met this criteria $(\mathrm{N}=7)$ for reading the full text. We 
identified an additional 11 articles from the reference lists of these seven articles, and a further 12 articles which were known to the authors or to attendees of the workshop "Towards a general theory of pace-of-life syndrome" (see ESM Fig. S1 for PRISMA flow diagram).

We thus selected a total of 30 papers for reading full text based on our search criteria. KJM and WEF independently read each of these 30 papers to evaluate whether they should be included in the systematic review. We established that models should meet all three of the following criteria in order to address the evolution or development of POLS within populations:

\section{The study presents a formal model that includes a POL trait. POL refers to covariances between LH traits} resulting from a current-future reproduction trade-off. We considered two ways of capturing this trade-off: (a) as a single trait that allows only for certain combinations of trait values (e.g. the couples of early reproduction/low survival and late reproduction/high survival), and not for others (e.g. early reproduction/high survival and late reproduction/low survival); and (b) as two separable life-history traits (i.e. survival and reproduction), such that all combinations of reproduction and survival were in principle possible. However, a current-future reproduction trade-off was implicit such that within individuals, a higher investment in current reproduction implied a lower investment in future reproduction. We excluded models with discrete, non-overlapping generations (i.e. a single reproductive event per lifetime), because these do not allow for a current-future reproduction trade-off.

\section{There was at least one additional trait in the model that could represent a behavioural and/or physiological} trait. This criterion was met either when a paper explicitly described a trait as behavioural and/or physiological, or when the assumptions and descriptions of a model parameter were sufficiently general that even when not described as a behavioural or physiological trait, the parameter could be viewed as representing such a trait. For example, a parameter that describes resource level in the environment and whose level can vary could also be taken to represent among-individual variation in the ability to monopolize resources (e.g. due to variation in dominance).

\section{The model evaluated the covariance between the POL trait and the behavioural and/or physiological trait.}

This criterion was met either if the covariance structure between LH traits and the additional trait was explicitly quantified, or if the covariance structure could be extrapolated based on information provided in the text. For some models, covariances between the LH trait and the behavioural and/or physiological trait were imposed by the model assumptions (i.e. the relationship between the two traits is fixed), rather than evolutionary outcomes. We did not consider that such models address the evolution or development of POLS. 
KJM and WEF resolved any discrepancies in the evaluation of whether or not a given study met each of these criteria by discussion. Table 1 summarizes each of the 30 full texts evaluated for the three above-mentioned criteria.

\section{Within-population models of POLS: within-individuals versus among-individuals}

Our systematic review yielded only 8 papers (one of which included two relevant models) of formal models of POLS, i.e. which address the evolution of covariances between LH traits and additional behavioural and/or physiological traits while assuming a trade-off between current versus future reproduction. We summarize each of these models in Tables 2 and 3, highlighting aspects of the model assumptions and predictions that are crucial to developing empirical tests of the models. These models address the evolution of covariance between LH and behavioural and/or physiological traits at two different levels of biological organisation: 1) within-individuals (Houston and McNamara 1989; Clark 1994), and 2) among-individuals within the same population (van Noordwijk and de Jong 1986; de Jong and van Noordwijk 1992; de Jong 1993; Wolf et al. 2007b; van Doorn et al. 2009; Engqvist et al. 2015).

The three models addressing POLS (derived from two papers: Houston and McNamara 1989; Clark 1994) at the within-individual level have common features. Both use stochastic dynamic programming (Mangel and Clark 1988; Houston and McNamara 1999) to model risk-taking (specifically, a trait that increases resource acquisition at the expense of increased probability of mortality) as a function of residual reproductive value (RRV), where RRV represents the ratio of expected future reproduction to expected current reproduction. Both models involve asset protection, whereby individuals with high assets (i.e. high RRV) are risk averse (i.e. avoid variability in outcomes) to protect their assets. Although neither of these models evaluates the long-term consistency of risktaking, among-individual variation in RRV and risk-taking would be expected to erode over time given that asset protection is a negative-feedback mechanism (McElreath et al. 2007; Luttbeg and Sih 2010) (but see Wolf et al. 2007a for a discussion of why negative feedbacks may not always erode among-individual differences). Thus, the patterns of covariance predicted at the within-individual level by these models cannot be extrapolated to predict patterns of covariance at the among-individual level.

We identified six models that address covariances between LH and behavioural and/or physiological traits at the among-individual, within-population level. Four of these models did not address POLS for repeatedly expressed behavioural and/or physiological traits. In the models by van Noordwijk and de Jong (van Noordwijk and de 
Jong (1986); de Jong and van Noordwijk (1992); de Jong (1993)), the additional trait (resource acquisition) is expressed only once per lifetime. Similarly, in the model by van Doorn et al. (2009), consistency of the trait expression (foraging) is an assumption, rather than an outcome, of the model. Therefore, these models cannot illuminate when individuals would be expected to exhibit consistent among-individual differences in a repeatedly expressed trait, and when the average expression of such traits is expected to co-vary with LH traits. However, most empirical tests of POLS (see reviews by Montiglio et al. 2017; Royauté et al. 2017), consider covariances between LH and behavioural and/or physiological traits that are expressed repeatedly throughout an individual's lifetime (e.g. activity, foraging boldness, parental care, aggression, metabolic rate, etc.).

We found only two models that address the evolution of POLS for repeatedly expressed behavioural and/or physiological traits (Wolf et al. 2007b; Engqvist et al. 2015). The model by Engqvist et al. (2015) analyzes the conditions under which males of varying degrees of attractiveness (i.e. reproductive value) should signal for mates (a "risky" behaviour in that it increases access to potential mates at the cost of increased probability of mortality due to predation). The model by Wolf et al. (2007b) analyzes the co-evolution of pace-of-life (early versus late reproduction) and two "risky" behaviours: foraging boldness and conspecific aggression. These models share several key features. Both assume frequency- and density-dependent payoffs to alternative behavioural tactics and both models limit the scope for negative feedbacks to erode among-individual differences in reproductive value. In the model by Wolf et al. (2007b), behavioural actions in the first hawk-dove game (i.e. foraging boldness) influence their reproductive value, which in turn affect their optimal level of aggression in the second hawk-dove game. However, the magnitude of these effects is assumed to be small, such that negative feedbacks between state and behaviour can never negate differences in reproductive value caused by differences in life history strategy. The Engqvist et al. (2015) model does not allow for any negativefeedbacks between state and behaviour; risky-signalling for mates does not produce any lasting effect on male attractiveness independent of the signalling itself. The models both predict that individuals with a fast POL will have consistently higher levels of risk-taking behaviours compared to individuals with a slow POL.

These two models also differ in several ways. Wolf et al. (2007b) address covariances between POL and two additional traits, while Engqvist et al. (2015) address covariances between POL and one additional trait. The Engqvist et al. (2015) model emphasizes which changes in parameter values are required to alter the predicted covariance structure. It shows that the predicted covariance between POL and risk-taking reverses when differences in baseline mortality between attractive and unattractive males are small (i.e. when the trade-off between reproduction and survival is weak). Additionally, in the Engqvist et al. (2015) model lifespan varies 
probabilistically among individuals as a function of their attractiveness, their level of risk-taking, and the frequency of their types in a population. In the Wolf et al. (2007b) model, maximum lifespan is fixed at two reproductive periods (for discussion of developmental modeling of many time periods, including incremental learning about the environmental state, see Stamps and Frankenhuis 2016).

\section{What the current models do not teach us}

Given the number of empirical studies aimed at testing POLS at the among-individual, within-population level (reviewed in Royauté et al. 2017), the scarcity of formal theory is surprising. Here, we highlight two major gaps in the existing modeling literature.

\section{What types of behavioural and/or physiological traits co-evolve with POL?}

The POLS hypothesis predicts covariation between LH traits and multiple, diverse, behavioural, and physiological traits. However, we find that existing models of POLS address covariation of LH traits with a small number of additional traits (one or two), and moreover, these (non-LH) traits share a key characteristic: they directly affect resource acquisition. In some cases, and increase in resource acquisition is traded off against survival (Houston and McNamara 1989; Clark 1994; Wolf et al. 2007b; Engqvist et al. 2015), and in others, there was no direct consequence for survival (van Noordwijk and de Jong 1986; de Jong and van Noordwijk 1992; de Jong 1993; van Doorn et al. 2009).

In their paper, Réale et al. (2010) list 13 potential traits for integration within the POLS framework (seven behavioural, six physiological). We suggest that the payoff structures (how the trait value affects fitness-relevant parameters, such as survival probability and resource levels) used in current models of POLS apply to a limited number of these traits. For example, greater foraging boldness may increase resource acquisition at the expense of increased probability of mortality due to predation, and increased metabolic rate may increase access to resources (but see Careau and Garland 2012; Mathot and Dingemanse 2015) at the cost of increased mortality due to higher rates of oxidative damage. However, other traits are likely to have different payoff structures. For example, increased immune function may cost resources but increase the probability of survival. For traits such as sociability or HPA axis reactivity, the probable effects on resource acquisition (or net resource costs) and survival are not obvious. Whether traits with these types of alternative payoff structures will also coevolve with POL is presently unclear. 
The current models of POLS do not allow for general conclusions about the processes that favour or hinder the development of POLS, in part because this set is small (eight models). Further, only two of these studies addressed POLS at the among-individual, within-population level for repeatedly expressed behavioural traits (Wolf et al. 2007b; Engqvist et al. 2015). In these two models, there is either no (Engqvist et al. 2015) or only limited (Wolf et al. 2007b) possibility for feedbacks between state (reproductive value or assets) and behaviour. They are also the only two studies to assume both frequency- and density-dependent payoffs (Table 2). Whether such assumptions are necessary to evolve POLS at the among-individual level for repeatedly expressed traits is currently unclear, and would require modification of these assumptions.

This relates to a general limitation of the current models of POLS: they explore a narrow parameter space.

Although each model summarized in Tables 2 and 3 included at least some exploration of changes in parameter values on model outcomes (Table 3), these were limited to modifying values for one or two parameters. A notable exception to this was the model developed by Engqvist et al. (2015), where there was extensive exploration of parameter space for multiple combinations of parameter values. If the goal of studying trait covariances within the POLS framework is to understand the processes that generate particular patterns of covariance, then exploration of parameters space is essential to illuminate when different processes can lead to the same outcome (Equifinality, see below) and when the same process can lead to different outcomes (Multifinality, see below). Explicit consideration of the effects of parameter values on model outcomes will provide more detailed predictions that may enable empiricists to discriminate between alternative processes, and will simultaneously emphasize the importance of matching empirical tests to model assumptions.

\section{Equifinality: Different processes, one outcome}

236 Our review shows that POLS can emerge via at least two distinct processes: (1) a direct trade-off between

237 current and future reproduction (Houston and McNamara 1989; Clark 1994; Wolf et al. $2007 \mathrm{~b}$; van Doorn et al. 2009), or (2) a direct trade-off between current reproduction and survival (van Noordwijk and de Jong 1986; de Jong and van Noordwijk 1992; de Jong 1993; Engqvist et al. 2015). In the former case, the covariance between LH parameters (e.g. age at first reproduction and survival) results from interacting model assumptions. In the latter models, covariance between LH traits is assumed (i.e. fixed combinations of trait values). 
We also identified three models that involved neither of the aforementioned trade-offs, but which nonetheless predict trait covariances that match predictions from POLS (Stamps et al. 1998; Mangel and Stamps 2001; Mullon et al. 2016). For example in the models by Stamps et al. (1998) and Mangel and Stamps (2001), organisms face a trade-off between growth and survival, which results in covariances between age at first reproduction, survival, and morphological characteristic (see Hämäläinen et al. 2017 for discussion of integrating morphology into the POLS framework). The model by Mullon et al. (2016), in which one trait has positive indirect fitness benefits and the second trait increases pairwise relatedness (i.e. when two individuals that show an increase in the value of a trait have a greater probability of being related than two randomly selected individuals), predicts positive covariances that match POLS predictions (i.e. higher survival associated with lower dispersal and greater helping behaviour). This prediction highlights that observations of particular patterns of covariance between $\mathrm{LH}$ and additional traits do not allow for strong inferences about the processes generating these patterns. If the same patterns of covariance can arise via multiple processes, how can we increase our understanding of the processes generating patterns of trait covariance observed in biological systems? We suggest that changing the focus of current models from "can POLS evolve?" (i.e. proofs of principle) to "when do POLS evolve?" (i.e. what processes give rise to POLS depending on environmental context and the organism's state, and in what conditions are these processes likely to eclipse other processes that erode POLS) will help in achieving this aim (see also Montiglio et al. 2017). Ideally, modellers would also stipulate how model assumptions might be tested, and explicitly list suitable empirical systems, which satisfy their models' assumptions.

\section{Multifinality: one process, different outcomes}

Of the models summarized in Tables 2 and 3, those that involved the most detailed exploration of parameter space (van Noordwijk and de Jong 1986; de Jong and van Noordwijk 1992; de Jong 1993; Engqvist et al. 2015) also highlight that the same process can lead to different outcomes. For example, the models by de Jong and van Noordwijk (van Noordwijk and de Jong (1986); de Jong and van Noordwijk (1992); de Jong (1993)) illustrate how changing the degree of among-individual variation in resource acquisition can change the covariance between two life history traits linked via a trade-off. When among-individual differences in resource acquisition are small relative to the among-individual variance in allocation, the correlation between LH traits amongindividuals reflects the within-individual trade-off (i.e. there is a negative correlation between survival and reproduction). However, when the among-individual differences in resource acquisition are relatively large, the 

among-individual level. This insight has been tremendously influential (Metcalfe 2016).

274

Engqvist et al. (2015) similarly show that the specific combinations of parameter values can have large effects on predicted trait covariances. When the POL-related differences in baseline mortality are large, the predicted covariance between POL and risk-taking is consistent with the prediction of Réale et al. (2010) that fast POL will be associated with greater risk-taking. However, when the POL-related differences in baseline mortality are small, individuals with a slow POL are predicted to be more risk-taking. This result arises because when differences in baseline mortality are large, the cost to individuals with high reproductive value (attractive males) of signaling in the presence of predators is relatively small, and therefore, attractive males signal. In contrast, when the differences in baseline mortality are low, the cost of signalling for mates in the presence of predators is large (relative to baseline mortality). As attractive males have more reproductive assets to protect, there is selection against signaling by attractive males in the presence of predators. This trade-off results in a relaxed competitive environment for unattractive males which favours greater signalling for mates by unattractive males under predation risk. By highlighting that model assumptions and parameter values influence predicted trait covariances, these papers provide more detailed predictions for empiricists (e.g. positive covariance expected under condition $x$, but negative covariance under condition $y$ ). They also provide a reminder of the critical importance of matching empirical tests to model assumptions.

\section{Guide for empiricists}

Scientific progress depends on a good fit between theory and data. In Table 2, we highlighted several aspects of model assumptions that are relevant in devising sound empirical tests of theory, such as the type of trait represented, whether payoffs are frequency- or density-dependent, the level of biological variation, etc. Here, we discuss some assumptions of existing models in order to provide guidelines that can aid in the development of empirical tests that are well matched to theory. Predictions arising from the existing set of POLS models are summarized in Table 3.

The POLS concept develops verbal predictions for covariances between POL and a range of behavioural and physiological traits. However, the formal models of POLS are relevant for only a subset of the traits outlined in Réale et al. (2010). Empiricists should be careful to ensure that the traits they study are likely to show the type(s) of relationships and payoff structure(s) assumed by the models. In other words, before testing model predictions, 
301

302

303

304

305

306

307

308

309

310

311

312

313

314

315

316

317

318

319

320

321

322

323

324

325

326

327

328

329

empiricist should first examine, and ideally test, model assumptions in their system. For all existing models, the additional non-LH trait increases access to resources, and either decreases survival or has no effect on survival. Thus, for many behavioural and physiological traits (e.g. immune function, HPA axis reactivity, sociability, etc.), there are in fact no formal predictions regarding their expected covariance with LH traits, and therefore, quantification of their covariance with LH traits does not constitute a test of extant formal POLS theory.

Focusing on the payoff structures incorporated into models when selecting traits will help empiricist avoid socalled 'jingle-jangle fallacies', when a single trait label describes two functionally different traits or when two different labels actually describe the same trait (Carter et al. 2013). For example, in the model by Wolf et al. (2007b), the POL trait is called 'exploration', and the model predicts covariance between 'exploration' and risktaking behaviours. However, in the animal personality literature, exploration is typically a measure of how an organism moves through a novel environment (Réale et al. 2007), not a measure of their life-history strategy. In fact, a recent meta-analysis reveals that exploration does not reliably co-vary with measures of reproductive performance or survival (Smith and Blumstein 2008). Thus, the validity of using exploration as a proxy for POL requires testing on a system-by-system basis. Testing for covariation between exploration (of a novel environment) and risk-taking does not constitute a test of the Wolf et al. (2007b) model, nor does a positive covariation constitute support for it, unless the assumption that exploration reflects POL has been tested.

In addition to choosing traits whose payoffs structures are properly captured by existing models, assumptions related to the timing of their effects on resource (acquisition or allocation) and survival should be matched to the biology of the empirical system. For example, in the Engqvist et al. (2015) model, resources gained by risky mate signalling behaviour are converted instantly to reproductive output, reproductive assets do not accrue. In the Wolf et al. (2007b) model, resources gained by risk-taking behaviour can accrue between year 1 and year 2, but the potential increase in asset is small compared with differences caused by differences in life history strategy. These may be valid assumptions when considering the risk-taking behaviour of income breeders during the reproductive period, where the entire energy requirements for current reproduction are met by current energy intake. It may similarly apply to risky-signalling for mates, as described in the Engqvist et al. (2015) model: signalling for mates now increases access to mates now, but has no carry-over effect on access to mates in future reproductive bouts. In contrast, behaviour outside of the reproductive period by definition is not converted immediately to reproductive output, and therefore, should be expected to affect reproductive assets in ways that feedback to influence risk-taking (McElreath et al. 2007). 
Similarly, the assumption that the accrued assets will be small relative to differences in assets associated with life-history decisions (Wolf et al. 2007b) may be unrealistic for behaviours that are expressed repeatedly between reproductive bouts (e.g. foraging boldness). For example, the assets that might be gained from a single expression of foraging boldness may reasonably be expected to have small effects on assets relative to differences in assets associated with life history strategy. However, the cumulative effect of hundreds of instances of risk-taking decisions between two reproductive bouts may be more reasonably expected to have potentially large effects on assets. In fact, many empirical "tests" of POLS involve traits where the assumption of no (or limited) feedback between behaviour and assets is unlikely to be upheld (e.g. foraging boldness during the non-breeding season).

\section{Conclusions}

We conclude that there is, at present, little formal theory about POLS. Further, the only two models of POLS at the within-individual, among-population level for repeatedly expressed traits (Wolf et al. 2007b; Engqvist et al. 2015), although pioneering and insightful, shared numerous characteristics that limit the range of empirical applications. Both models address covariance between POL and a trait that increases access to resource at the cost of increased probability of mortality (e.g. due to predation) (or two additional traits in the case of Wolf et al. 2007b). At the same time, they explicitly do not allow (Engqvist et al. 2015) or limit (Wolf et al. 2007b) feedbacks between behaviour and reproductive value. We discuss scenarios where these assumptions are likely to be met and which, therefore, would constitute the best possible tests of the existing theory. However, we also point out that many studies that aim to test POLS do not satisfy these model assumptions, hence it is unclear how much support exists for current theory. Future modelling work can contribute to our understanding of POLS by shifting focus from demonstrating that POLS can evolve, to demonstrating when POLS evolve (providing a flashlight for empiricists), and by modelling a wider range of traits (e.g. immunity, sociability, etc.).

\section{References}

Baldauf SA, Engqvist L, Weissing FJ (2014) Diversifying evolution of competitiveness. Nature Communications $5: 5233$ 
Baldini R (2015) Harsh environments and "fast" human life histories: What does the theory say? bioRxiv https://doiorg/101101/014647

Bell AM, Hankison SJ, Laskowski KL (2009) The repeatability of behaviour: a meta-analysis. Anim Behav $77: 771-783$

Belsky J, Steinberg L, Draper P (1991) Childhood Experience, Interpersonal Development, and Reproductive Strategy: An Evolutionary Theory of Socialization. Child Development 62:647-670

Biro PA, Stamps JA (2008) Are animal personality traits linked to life-history productivity? Trends Ecol Evol $23: 361-368$

Biro PA, Stamps JA (2010) Do consistent individual differences in metabolic rate promote consistent individual differences in behavior? Trends Ecol Evol 25:653-659

Careau V, Garland T (2012) Performance, personality, and energetics: Correlation, causation and mechanism. Physiol Biochem Zool 85:543-571

Careau V, Thomas DK, Humphries MM, Réale D (2008) Energy metabolism and animal personality. Oikos 117:641-653

Carter AJ, Feeney WE, Marshall HH, Cowlishaw G, Heinsohn R (2013) Animal personality: what are behavioural ecologists measuring? Biol Rev 88:465-475

Chan MHT, Kim PS (2014) An age-structured approach to modelling behavioural variation maintained by lifehistory trade-offs. Plos One 9

Charlesworth B (1990) Optimization models, quantitative genetics, and mutation. Evolution 44:520-538

Clark CW (1994) Antipredator behavior and the asset-protection principle. Behav Ecol 5:159-170

Dammhahn M, Dingemanse NJ, Niemelä P, Réale D (2017) Pace-of-life syndromes: a framework for the adative integration of personality and life-history. Behav Ecol Sociobiol

de Jong G (1993) Covariances between traits deriving from successive allocations of a resource. Funct Ecol $7: 75-83$

de Jong G, van Noordwijk AJ (1992) Acquisition and allocation of resources: genetic (co) variances, selection, and life histories. Am Nat 139:749-770

Del Giudice M, Gangestad SW, Kaplan HS (2015) Life history theory and evolutionary psychology. In: Buss DM (ed) The handbook of evolutionary psychology. Wiley, New York, pp 88-114

Delaguerie P, Olivieri I, Atlan A, Gouyon PH (1991) Analytic and simulation-models predicting positive genetic correlations between traits linked by trade-offs. Evolutionary Ecology 5:361-369 
Ellis BJ, Figueredo AJ, Brumbach BH, Schlomer GL (2009) Fundamental Dimensions of Environmental Risk. Human Nature 20:204-268

Engqvist L, Cordes N, Reinhold K (2015) Evolution of risk-taking during conspicuous mating displays. Evolution 69:395-406

Frankenhuis WE, Panchanathan K, Clark Barrett H (2013) Bridging developmental systems theory and evolutionary psychology using dynamic optimization. Developmental Science 16:584-598

Hämäläinen A, Immonen E, Schuett W, Tarka M (2017) Sex-specific secltion and teh evolution of pace-of-life syndromes. Behav Ecol Sociobiol

Holtmann B, Lagisz M, Nakagawa S (2016) Metabolic rates, and not hormone levels, are a likely mediator of between-individual differences in behaviour: a meta-analysis. Funct Ecol:n/a-n/a

Houle D (1991) Genetic covariance of fitness correlates: what genetic correlations are made of and why it matters. Evolution 45:630-648

Houston AI, McNamara JM (1989) The value of food: effects of open and closed economies. Anim Behav $37: 546-562$

Houston AI, McNamara JM (1999) Models of adaptive behaviour: an approach based on state. Cambridge University Press, Cambridge

Jonsson KI, Tuomi J, Jaremo J (1998) Pre- and postbreeding costs of parental investment. Oikos 83:424-431

Luttbeg B, Sih A (2010) Risk, resources and state-dependent adaptive behavioural syndromes. Philos Trans R Soc B 365:3977-3990

Mallpress DEW, Fawcett TW, Houston AI, McNamara JM (2015) Risk attitudes in a changing environment: an evolutionary model of the fourfold pattern of risk preferences. Psychological Review 122:364-375

Mangel M, Clark CW (1988) Dynamic modeling in behavioral ecology. Princeton University Press

Mangel M, Stamps J (2001) Trade-offs between growth and mortality and the maintenance of individual variation in growth. Evol Ecol Res 3:583-593

Martin LBI, Hasselquist D, Wikelski M (2006) Investment in immune defense is linked to pace of life in house sparrows. Oecologia 147:565-575

Mathot KJ, Dingemanse NJ (2015) Behaviour and energetics: unrequited needs and new directions. Trends Ecol Evol 30:199-206

McElreath R, Luttbeg B, Fogarty SP, Brodin T, Sih A (2007) Evolution of animal personalities. Nature 450:E5

McElreath R, Strimling P (2006) How noisy information and individual asymmetries can make 'personality' an adaptation: a simple model. Anim Behav 72:1135-1139 
McNamara JM, Houston AI (1996) State-dependent life histories. Nature 380:215-221

Metcalfe CJ (2016) Invisible trade-offs: van Noordwijk and de Jong and life-history evolution. Am Nat 187:iii-v

Moher D, Liberati A, Tetzlaff J, Altman DG, The PG (2009) Preferred Reporting Items for Systematic Reviews and Meta-Analyses: The PRISMA Statement. PLOS Medicine 6:e1000097

Montiglio PO, Dammhahn M, Dubuc Messier G, Réale D (2017) The pace-of-life syndrome hypothesis: evidence, limitations and future directions. Behav Ecol Sociobiol

Mullon C, Keller L, Lehmann L (2016) Evolutionary stability of jointly evolving traits in subdivided populations. The American Naturalist 188:175-195

Réale D, Garant D, Humphries MM, Bergeron P, Careau V, Montiglio P-O (2010) Personality and the emergence of the pace-of-life syndrome concept at the population level. Philos Trans R Soc B $365: 4051-4063$

Réale D, Reader SM, Sol D, McDougall PT, Dingemanse NJ (2007) Integrating animal temperament within ecology and evolution. Biol Rev 82:291-318

Ricklefs RE (2000) Lack, Skutch, and Moreau: The Early Development of Life-History Thinking. The Condor 102:3-8

Ricklefs RE, Wikelski M (2002) The physiology/life-history nexus. Trends Ecol Evol 17:462-469

Riska B (1986) Some models for development, growth, and morphometric correlation. Evolution 40:1303-1311

Royauté R, Berdal MA, Garrison C, Dochtermann NA (2017) Paceless life? A meta-analysis of the "Pace-ofLife syndrome". Behav Ecol Sociobiol

Saether B-E (1988) Pattern of covariation between life-history traits of European birds. Nature 331:616-617 Sibly R, Calow P (1984) Direct and absorption costing in the evolution of life cycles. J Theor Biol 111:463-473

Smith BR, Blumstein DT (2008) Fitness consequences of personality: a meta-analysis. Behav Ecol 19:448-455

Stamps J, Phillips JA, Mangel M (1998) A New Look at Relationships between Size at Maturity and Asymptotic Size. Am Nat 152:470-479

Stamps JA (2007) Growth-mortality tradeoffs and 'personality traits' in animals. Ecol Lett 10:355-363

Stamps JA, Frankenhuis WE (2016) Bayesian Models of Development. Trends Ecol Evol 31:260-268

Stearns SC (1992) The evolution of life histories. Oxford University Press, Oxford

Teriokhin AT (1998) Evolutionarily optimal age schedule of repair: Computer modelling of energy partition between current and future survival and reproduction. Evolutionary Ecology 12:291-307 
447

van Doorn GS, Wolf M, Leimar O, Weissing FJ (2009) Animal personalities and the divergence of life-histories. In Adaptive individual differences. In: Faculty of Mathematics and Natural Sciences. University of Groningen, the Netherlands

van Noordwijk AJ, de Jong G (1986) Acquisition and allocation of resources: their influence on variatio in life history tactics. Am Nat 128:137-142

Williams GC (1966) Natural selection, the costs of reproduction, and a refinement of Lack's principle. The American Naturalist 100:687-690

Wolf M, McNamara JM (2012) On the evolution of personalities via frequency-dependent selection. Am Nat 179:679-692

Wolf M, van Doom GS, Leimar O, Weissing FJ (2007a) Wolf et al. reply. Nature 450:E5-E6

Wolf M, van Doorn GS, Leimar O, Weissing FJ (2007b) Life-history trade-offs favour the evolution of animal personalities. Nature 447:581-584

Wolf M, van Doorn GS, Weissing FJ (2008) Evolutionary emergence of responsive and unresponsive personalities. PNAS 105:15825-15830

Wolf M, Van Doorn GS, Weissing FJ (2011) On the coevolution of social responsiveness and behavioural consistency. Proc R Soc B 278:440-448

Worley AC, Houle D, Barrett SCH (2003) Consequences of hierarchical allocation for the evolution of lifehistory traits. Am Nat 161:153-167 
Table 1 Overview of papers that were evaluated in the context of POLS

\begin{tabular}{|c|c|c|c|c|}
\hline \multirow[b]{2}{*}{ Reference } & \multicolumn{3}{|c|}{ POLS criteria } & \multirow{2}{*}{$\begin{array}{l}\text { Model attributes } \\
\text { summarized in } \\
\text { Tables } 2 \& 3^{d}\end{array}$} \\
\hline & $\mathrm{POL}^{\mathrm{a}}$ & $\begin{array}{l}\text { Additional } \\
\text { trait(s) }\end{array}$ & $\begin{array}{l}\text { Covariances } \\
\text { evaluated }^{c}\end{array}$ & \\
\hline Baldauf et al. (2014) & $N(D)$ & $Y(1)$ & NA & $\mathrm{N}$ \\
\hline Baldini (2015) & $Y(A)$ & $\mathrm{N}$ & NA & $\mathrm{N}$ \\
\hline Chan and Kim (2014) & $Y(A)$ & $Y(1)$ & 1 & $\mathrm{~N}$ \\
\hline Charlesworth (1990) & $Y(A)$ & $\mathrm{N}$ & NA & $\mathrm{N}$ \\
\hline Clark (1994) & $Y(R R V)$ & $\mathrm{Y}(1)$ & $\mathrm{Y}$ & $\mathrm{Y}$ \\
\hline de Jong and van Noordwijk (1992) & $Y(A)$ & $Y(1)$ & $\mathrm{Y}$ & $\mathrm{Y}$ \\
\hline de Jong (1993) & $Y(A)$ & $\mathrm{Y}(1)$ & $\mathrm{Y}$ & $\mathrm{Y}$ \\
\hline Delaguerie et al. (1991) & $Y(A)$ & $\mathrm{N}$ & $\mathrm{N}$ & $\mathrm{N}$ \\
\hline $\begin{array}{l}\text { Engqvist et al. (2015) } \\
\text { I. All else being equal model } \\
\text { II. higher baseline mortality for } \\
\text { attractive males }\end{array}$ & $\begin{array}{l}\mathrm{N}^{\mathrm{h}} \\
\mathrm{Y}\end{array}$ & $\begin{array}{l}Y(1) \\
Y(1)\end{array}$ & $\mathrm{Y}$ & $\begin{array}{l}N \\
Y\end{array}$ \\
\hline Frankenhuis et al. (2013) & $Y(A)$ & $\mathrm{N}$ & NA & $\mathrm{N}$ \\
\hline Houle (1991) & $N(D)$ & $\mathrm{Y}(1)$ & NA & $\mathrm{N}$ \\
\hline Houston and McNamara (1989) & $Y(R R V)$ & $Y(2)$ & $\mathrm{Y}$ & $\mathrm{Y}$ \\
\hline Jonsson et al. (1998) & $Y(A)$ & $\mathrm{N}$ & NA & $\mathrm{N}$ \\
\hline Luttbeg and $\operatorname{Sih}(2010)$ & $N(D)$ & $Y(1)$ & NA & $\mathrm{N}$ \\
\hline Mangel and Stamps (2001) & $N(E)$ & $\mathrm{Y}^{\mathrm{g}}(1)$ & $\mathrm{Y}$ & $\mathrm{N}$ \\
\hline Mallpress et al. (2015) & $Y(A)$ & $\mathrm{Y}(1)$ & $\mathrm{N}^{\mathrm{f}}$ & $\mathrm{N}$ \\
\hline McElreath and Strimling (2006) & $N(D)$ & $\mathrm{Y}(1)$ & NA & $\mathrm{N}$ \\
\hline McNamara and Houston (1996) & $\mathrm{Y}(\mathrm{RRV})$ & $\mathrm{N}$ & NA & $\mathrm{N}$ \\
\hline Mullon et al. (2016) & $N(E)$ & $Y(1)$ & $\mathrm{Y}$ & $\mathrm{N}$ \\
\hline Riska (1986) & $Y(A)$ & $\mathrm{N}$ & NA & $\mathrm{N}$ \\
\hline Sibly and Calow (1984) & $Y(A)$ & $\mathrm{N}$ & NA & $\mathrm{N}$ \\
\hline Stamps et al. (1998) & $N(E)$ & $\mathrm{Y}^{\mathrm{g}}(1)$ & $\mathrm{Y}$ & $\mathrm{N}$ \\
\hline Teriokhin (1998) & $Y(A)$ & $Y(1)$ & $\mathrm{N}$ & $\mathrm{N}$ \\
\hline van Doorn et al. (2009) & $\mathrm{Y}$ & $\mathrm{Y}(1)$ & $\mathrm{Y}$ & $\mathrm{N}$ \\
\hline van Noordwijk and de Jong (1986) & $Y(A)$ & $Y(1)$ & $\mathrm{Y}$ & $\mathrm{Y}$ \\
\hline Wolf and McNamara (2012) & $N(D)$ & $Y(2)$ & NA & $\mathrm{N}$ \\
\hline Wolf et al. (2008) & $N(D)$ & $Y(1)$ & NA & $\mathrm{N}$ \\
\hline Wolf et al. (2011) & $N(D)$ & $Y(2)$ & NA & $\mathrm{N}$ \\
\hline Wolf et al. (2007b) & $Y(S T)$ & $Y(2)$ & $\mathrm{Y}$ & $\mathrm{Y}$ \\
\hline Worley et al. (2003) & $Y(A)$ & $\mathrm{N}$ & NA & $\mathrm{N}$ \\
\hline
\end{tabular}

a. Is the trade-off between current and future reproduction implicit in the model assumptions? Yes (Y) or No (N). The implicit trade-off can be modelled either as a single trait that captures the trade-off (ST) (e.g. trait values are either early reproduction/low survivals or late reproduction/high survival), residual reproductive value (RRV), or as an allocation decision (A). Allocation decision can be directly between current and future reproduction, or between current reproduction and survival as these are nested within current/future reproduction trade-offs (i.e. if you die, you necessarily cannot reproduce). Note however that current/future reproduction trade-offs do not necessarily imply differences in survival. Models did not meet the LH trade-off criteria if they did not allow for variation in investment to current versus future reproduction because models were structured with discrete non-overlapping generations (D), or because there was no implicit trade-off 
b. Additional trait(s): were additional traits considered in the models that can be interpreted as either behavioural and/or physiological traits. Number of additional traits is provided in parentheses

c. Was the covariance between the LH traits and the additional trait(s) evaluated? Not applicable (NA) if either $\mathrm{LH}$ trait or additional trait is absent, yes $(\mathrm{Y})$ if the model directly evaluates covariance structure between $\mathrm{LH}$ and additional trait, or covariance structure can be directly extrapolated based on information provided in the text, no $(N)$ if the model neither directly evaluates covariance structure nor is information directly available in current results, or imposed $(\mathrm{I})$ if covariance between traits is imposed by the model assumptions in such a way that only a single covariance is possible (e.g. trait A trait B + constant)

d. Model attributes summarized in Table 2, predictions outlined in Table 3: Yes ( $\mathrm{Y}$ ) or No (N). Models were selected for more detailed summaries if they met all four criteria for POLS at the within-population level. We additionally included models that met all criteria except for evaluating the consistency in trait expression over the lifetime of individuals as these may be relevant for understanding POLS at different levels of variation (e.g.

491 among-populations or within-individuals) (see Table 2)

492

493

494

495

496

497 e. Analyses predict fixation of trait R (allele for resource acquisition), therefore, no possibility for genetic covariance between resource acquisition and allocation $(C)$ between reproduction and survival. Phenotypic variance in $\mathrm{R}$ is all due to stochastic processes

f. Consistency and/or covariances not evaluated for the traits relevant for POLS (e.g. consistency of POL or additional trait, or covariance between POL and additional trait)

g. additional trait is body size (morphological, not behavioural or physiological)

h. In the model version where only attractiveness (i.e. reproductive value, RV) differs among males, variation in survival comes about because less attractive males are expected to be more risk-taking. This is not a POLS trait however, because there is no implicit trade-off between current and future reproduction, and the covariance between RV and survival that emerges from the model is opposite to the covariance that would be expected given the trade-off 
Table 2 Subset of papers summarized in Table 1 that met the three minimum criteria laid out for a model to address POLS. Additional details on model structure are provided

504 to facilitate interpretation of model applicability

\begin{tabular}{|c|c|c|c|c|c|c|c|c|c|c|}
\hline \multirow[b]{2}{*}{ Ref } & \multirow[b]{2}{*}{$\begin{array}{l}\text { Source of initial } \\
\text { variation }^{a}\end{array}$} & \multicolumn{9}{|c|}{ Model attributes } \\
\hline & & Model type $^{b}$ & $\begin{array}{l}\text { Environment } \\
\text { structure }^{c}\end{array}$ & $\begin{array}{l}\text { Social } \\
\text { environment }^{d}\end{array}$ & Feedbacks $^{\mathrm{e}}$ & $\begin{array}{l}\text { Lagged } \\
\text { effects }^{f}\end{array}$ & $\begin{array}{l}\text { Additional } \\
\text { factors }\end{array}$ & $\begin{array}{l}\text { Inheritance } \\
\text { system }^{\mathrm{g}}\end{array}$ & $\begin{array}{l}\text { Consistency } \\
\text { evaluated }\end{array}$ & $\begin{array}{l}\text { Applicable } \\
\text { levels }\end{array}$ \\
\hline \multicolumn{11}{|l|}{ Clark $(1994)^{\mathrm{j}}$} \\
\hline $\begin{array}{l}\text { Continuous } \\
\text { reproduction }\end{array}$ & NA & $\begin{array}{l}\text { Stochastic } \\
\text { dynamic }\end{array}$ & No & No & Yes (-) & No & No & NA & No & WI \\
\hline $\begin{array}{l}\text { Growth and } \\
\text { episodic } \\
\text { reproduction }\end{array}$ & NS & $\begin{array}{l}\text { Stochastic } \\
\text { dynamic }\end{array}$ & No & No & Yes (-) & Yes & No & NA & No & WI \\
\hline de Jong (1993) & NS & Deterministic & No & No & No & No & No & NA & $N A^{k}$ & $A I^{m}$ \\
\hline $\begin{array}{l}\text { de Jong and van } \\
\text { Noordwijk } \\
(1992)\end{array}$ & $\begin{array}{l}\text { NS (genetic) } \\
\text { S(phenotypic) }\end{array}$ & Genetic & No & No & No & No & No & $\begin{array}{l}\text { Diploid, } \\
\text { single locus }\end{array}$ & $N A^{\prime}$ & $\mathrm{Al}^{\mathrm{m}}$ \\
\hline $\begin{array}{l}\text { Engqvist et al. } \\
\text { (2015) }\end{array}$ & NS & $\begin{array}{l}\text { Stochastic } \\
\text { dynamic }\end{array}$ & No & $\mathrm{FD}, \mathrm{DD}$ & No & No & No & NA & $\begin{array}{l}\text { Y (can be } \\
\text { inferred from } \\
\text { information } \\
\text { given in text) }\end{array}$ & $\mathrm{Al}$ \\
\hline $\begin{array}{l}\text { Houston and } \\
\text { McNamara } \\
\text { (1989) }\end{array}$ & NS & $\begin{array}{l}\text { Stochastic } \\
\text { dynamic }\end{array}$ & No & No & Yes (-) & No & $\begin{array}{l}\text { Yes } \\
\text { (metabolic } \\
\text { rate) }\end{array}$ & NA & No & WI \\
\hline $\begin{array}{l}\text { van Doorn et al. } \\
\text { (2009) }\end{array}$ & $M$ & $\begin{array}{l}\text { Individual- } \\
\text { based } \\
\text { simulation }\end{array}$ & $\begin{array}{l}\text { Yes (discrete } \\
\text { habitat } \\
\text { patches) }\end{array}$ & FD & $\begin{array}{l}\text { Yes (explore } \\
\text { both }+ \text { and -) }\end{array}$ & Yes & No & $\begin{array}{l}\text { Diploid, } \\
\text { multilocus }\end{array}$ & NA & $\mathrm{Al}$ \\
\hline $\begin{array}{l}\text { van Noordwijk } \\
\text { and de Jong } \\
(1986)\end{array}$ & NS & Deterministic & No & No & No & No & No & NA & $N A^{\prime}$ & $\mathrm{Al}^{\mathrm{m}}$ \\
\hline
\end{tabular}




\begin{tabular}{|c|c|c|c|c|c|c|c|c|c|c|}
\hline $\begin{array}{l}\text { Wolf et al. } \\
\text { (2007b) }\end{array}$ & $\begin{array}{l}\text { M (POL trait) } \\
\text { NS (behavioural } \\
\text { traits) Later } \\
\text { variation in } \\
\text { behavioural } \\
\text { traits also arises } \\
\text { via mutation }\end{array}$ & $\begin{array}{l}\text { Individual- } \\
\text { based } \\
\text { simulation }\end{array}$ & No & FD, DD & $\begin{array}{l}\text { Yes }(-), \text { but } \\
\text { effect is } \\
\text { constrained to } \\
\text { be small } \\
\text { relative to } \\
\text { differences } \\
\text { arising from } \\
\text { LH variation }\end{array}$ & Yesi & No & $\begin{array}{l}\text { H-ML, D- } \\
M L\end{array}$ & $\begin{array}{l}\text { Yes, but } \\
\text { under } \\
\text { restrictive } \\
\text { conditions } \\
\text { (traits } \\
\text { expressed } \\
\text { only twice in } \\
\text { lifetime) }\end{array}$ & $\mathrm{Al}$ \\
\hline
\end{tabular}

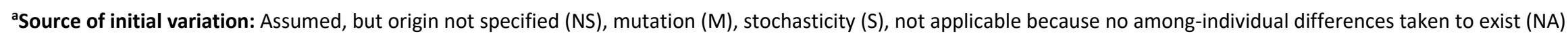

${ }^{\text {b} M o d e l ~ t y p e: ~ G e n e t i c ~(G), ~ D e t e r m i n i s t i c ~ s t a t e-d e p e n d e n t, ~ s t o c h a s t i c ~ d y n a m i c ~ s t a t e-d e p e n d e n t, ~(c o-) e v o l u t i o n a r y ~}$

'Environmental structure refers to attributes of the environment that affect all individuals simultaneously (e.g. high versus low resource availability, different patches, stochastic environmental fluctuations) but not to attributes that affect individuals singly (e.g. stochastic variation in prey encounter rates). Variation in these attributes must exist either within the lifetime of an individual (within-generation, WG), or of the lineage (among-generation, AG)

${ }^{\mathrm{d} S}$ Social environment: Is there social environment structure? Yes: Frequency dependent payoffs (FD), or density dependent payoffs (DD), or No

' Feedbacks: Yes: the output of trait $A$ affects the input for trait $B$, and vice versa. When the effect of $A$ on $B$ and of $B$ on $A$ are in the same direction (e.g. higher value of $A$ increases $B$, higher value of $B$ increases $A)$, the feedback is positive $(+)$, when they are in opposite directions, the feedback is negative (-)

'Lagged effects Yes: the consequences of behaviour for reproduction are delayed; No: the consequences are immediate. Y/N indicates that both lagged and non-lagged effects were explored

IInheritance system: Not applicable (NA, non-genetic model), haploid (H), diploid (D), single locus (SL), multi-locus (ML)

${ }^{\text {h} A p p l i c a b l e ~ l e v e l s: ~ w h a t ~ l e v e l ~ o f ~ v a r i a t i o n ~ w a s ~ t h e ~ m o d e l ~ c o n s t r u c t e d ~ t o ~ e x p l a i n ? ~ A m o n g ~-p o p u l a t i o n s ~(A P), ~ a m o n g-i n d i v i d u a l s ~ w i t h i n ~ t h e ~ s a m e ~ p o p u l a t i o n ~(A I), ~ w i t h i n-~}$

519 'Model involves many iterations in each of the two years of an individual's life, but the consequences of POL (exploration) in year 1 for resource level only emerge in year two. 
inote that (Clark 1994) involves multiple models 1) continuous reproduction (included because it addresses WI covariation), 2) growth and episodic reproduction included because it explores lagged effects

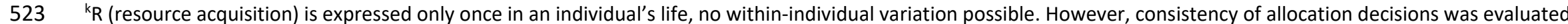

524 'R (resource acquisition) and c (allocation decision) each expressed only once in an individual's lifetime

mAlthough predicted covariances between LH and additional behavioural and/or physiological trait are applicable at the among-individual level, the additional trait is not expressed repeatedly in an individual's lifetime, and therefore the model does not address the stability of repeatedly expressed traits (i.e. animal personality) 
Table 3 Subset of papers summarized in Table 1 with details on model predictions

\begin{tabular}{|c|c|c|c|c|}
\hline Reference & POL & Additional trait(s) & Predicted covariance & Conditions \\
\hline & i.e. how POL is modelled & $\begin{array}{l}\text { i.e. how the paper describes the } \\
\text { additional trait }\end{array}$ & Between POL and additional trait & $\begin{array}{l}\text { i.e. parameter space } \\
\text { explored }\end{array}$ \\
\hline \multicolumn{5}{|l|}{ Clark (1994) } \\
\hline $\begin{array}{l}\text { Continuous } \\
\text { reproduction }\end{array}$ & $\mathrm{RRV}^{\mathrm{a}}$ & $\begin{array}{l}\text { Risk-taking while foraging } \\
\text { (implicit trade-off between } \\
\text { gaining resource and survival) }\end{array}$ & $\begin{array}{l}\text { Risk-taking increases with decreasing RRV. Animals } \\
\text { become more risk-taking as they age. Stability not } \\
\text { directly analyzed, but not expected based on } \\
\text { negative feedback }\end{array}$ & $\begin{array}{l}\text { Changing } \mathrm{T} \text { (maximum } \\
\text { number of time steps). }\end{array}$ \\
\hline $\begin{array}{l}\text { Growth and } \\
\text { episodic } \\
\text { reproduction) }\end{array}$ & $\mathrm{RRV}^{\mathrm{a}}$ & $\begin{array}{l}\text { Risk-taking (foraging tactics: } \\
\text { implicit trade-off between } \\
\text { gaining resources and survival) }\end{array}$ & $\begin{array}{l}\text { Stability of syndromes not analyzed } \\
\text { Generally, higher RRV favours lower risk-taking. }\end{array}$ & $\begin{array}{l}\text { Explore consequences of } \\
\text { different levels of starting } \\
\text { body mass }\end{array}$ \\
\hline de Jong (1993) & Allocations (successive) & $\begin{array}{l}\mathrm{R} \text { (resource availability) } \\
\text { Can be thought of as a } \\
\text { behavioural or physiological trait } \\
\text { that influences access to } \\
\text { resources }\end{array}$ & $\begin{array}{l}\text { Predicted covariance between fecundity and } \\
\text { survival at different points in time depend on mean } \\
\text { acquisition, variance in acquisition, and initial } \\
\text { allocation decision (see Figures } 3 \text { and } 4 \text { from de } \\
\text { Jong (1993) }\end{array}$ & $\begin{array}{l}\text { Explore consequences of } \\
\text { varying } R \text {, and varying } \\
\text { allocation decisions at } \\
\text { different times in life }\end{array}$ \\
\hline $\begin{array}{l}\text { de Jong and van } \\
\text { Noordwijk (1992) }\end{array}$ & Allocation & $\begin{array}{l}\mathrm{R} \text { (resource availability) } \\
\text { Can be thought of as a } \\
\text { behavioural or physiological trait } \\
\text { that influences access to } \\
\text { resources }\end{array}$ & $\begin{array}{l}\text { When there is large among-individual variance in } \mathrm{R} \text {, } \\
\text { among-individual covariation between reproduction } \\
\text { and survival is positive, and both co-vary positively } \\
\text { with R } \\
\text { When there is little among-individual variation in R, } \\
\text { reproduction and survival are negatively correlated. } \\
\text { There is no covariance with R (because R does not } \\
\text { vary, or varies little, among-individuals) }\end{array}$ & $\begin{array}{l}\text { Explore consequences of } \\
\text { varying } \mathrm{R} \text { among-individuals }\end{array}$ \\
\hline $\begin{array}{l}\text { Engqvist et al. } \\
\text { (2015) }\end{array}$ & $\begin{array}{l}\text { Parameter values for two } \\
\text { traits set to encompass }\end{array}$ & $\begin{array}{l}\text { Risky-signalling (signalling } \\
\text { behaviour to attract mates, }\end{array}$ & $\begin{array}{l}\text { When signalling costs are relatively low, fast POL } \\
\text { covaries positively with risky-signalling (boldness) }\end{array}$ & $\begin{array}{l}\text { Explore consequences of } \\
\text { varying differences in }\end{array}$ \\
\hline
\end{tabular}




\begin{tabular}{|c|c|c|c|c|}
\hline & $\begin{array}{l}\text { trade-off (baseline } \\
\text { mortality greater for males } \\
\text { with high reproductive } \\
\text { value) }\end{array}$ & $\begin{array}{l}\text { increases mating success but } \\
\text { increases predation rate) }\end{array}$ & $\begin{array}{l}\text { When differences in baseline mortality are low, } \\
\text { slow POL individuals are more risk-taking }\end{array}$ & $\begin{array}{l}\text { baseline mortality, explore } \\
\text { consequences of varying } \\
\text { predation costs of signalling }\end{array}$ \\
\hline $\begin{array}{l}\text { Houston and } \\
\text { McNamara } 1989^{3}\end{array}$ & $\begin{array}{l}\text { RRV (note that term used } \\
\text { in paper is expected future } \\
\text { reproductive success) }\end{array}$ & $\begin{array}{l}\text { g (gross rate of gain while } \\
\text { foraging, could reflect food } \\
\text { availability, or variation in } \\
\text { energy assimilation rates) } \\
\text { u (proportion of time allocated } \\
\text { to foraging, considered "risky" in } \\
\text { the sense that it increases risk of } \\
\text { predation relative to non- } \\
\text { foraging) }\end{array}$ & $\begin{array}{l}\text { Stability of syndromes not analyzed } \\
\text { Generally, higher RRV favours lower risk-taking. }\end{array}$ & $\begin{array}{l}\text { Explore consequences of } \\
\text { variation in gross energy } \\
\text { gain and energy reserves for } \\
\text { the relationship between } \\
\text { risk-taking and RRV }\end{array}$ \\
\hline $\begin{array}{l}\text { van Doorn et al. } \\
\text { (2009) }\end{array}$ & $\begin{array}{l}\text { Choice between current } \\
\text { versus future reproduction } \\
\text { (decision to breed } \\
\text { immediately or queue for a } \\
\text { territory) }\end{array}$ & $\begin{array}{l}\text { Foraging. Individuals can choose } \\
\text { between foraging under } \\
\text { predation risk (risk declines with } \\
\text { age), or under low risk (risk does } \\
\text { not vary with age) } \\
\text { Decision taken only once in an } \\
\text { individual's lifetime, switching is } \\
\text { not possible. }\end{array}$ & $\begin{array}{l}\text { Variation in POL and behaviour evolve first via } \\
\text { frequency-dependence. Then correlation evolves } \\
\text { such that individuals with a slow POL (those that } \\
\text { queue for reproduction) are expected to forage } \\
\text { under predation. When negative feedbacks } \\
\text { between assets and risk-taking are allowed, the } \\
\text { among-individual differences erode }\end{array}$ & $\begin{array}{l}\text { Explore consequences of }+ \\
\text { versus }- \text { feedbacks between } \\
\text { assets and risk-taking }\end{array}$ \\
\hline $\begin{array}{l}\text { van Noordwijk and } \\
\text { de Jong (1986) }\end{array}$ & Allocation & $\begin{array}{l}\mathrm{R}(\text { resource availability) } \\
\text { Can be thought of as a } \\
\text { behavioural or physiological trait } \\
\text { that influences access to } \\
\text { resources }\end{array}$ & $\begin{array}{l}\text { When there is large among-individual variance in } \\
\text { resource acquisition (R), higher } R \text { is associated with } \\
\text { higher fecundity and higher survival } \\
\text { When there is low-among-individual variance in } \\
\text { resource acquisition, higher fecundity is associated } \\
\text { with lower survival, but there is no covariance with } \\
R \text { (because } R \text { shows little variance) }\end{array}$ & $\begin{array}{l}\text { Explore consequences of } \\
\text { varying } \mathrm{R} \text { among-individuals }\end{array}$ \\
\hline Wolf et al. (2007b) & $\begin{array}{l}\text { Single trait encompassing } \\
\text { trade-off }^{c}\end{array}$ & $\begin{array}{l}\text { Two separate risk-taking } \\
\text { behaviours: }\end{array}$ & $\begin{array}{l}\text { Covariation between POL and risk-taking behaviours } \\
\text { arise due to state (POL)-dependent payoffs. Mix of }\end{array}$ & $\begin{array}{l}\text { Explore different payoff } \\
\text { combinations in anti- }\end{array}$ \\
\hline
\end{tabular}




\begin{tabular}{|l|l|l|l|l|}
\hline & & $\begin{array}{l}\text { Boldness/shyness } \\
\text { Aggressiveness (hawk/dove) }\end{array}$ & $\begin{array}{l}\text { types maintained in populations via frequency- and } \\
\text { density-dependence }\end{array}$ & $\begin{array}{l}\text { predator and hawk-dove } \\
\text { game }\end{array}$ \\
\hline
\end{tabular}

${ }^{\mathrm{a} R \mathrm{~V}}=$ residual reproductive value, the ratio of expected future reproduction to expected current reproduction

529 bIndividuals have a total finite resource amount available, which they can allocate to current reproduction (fecundity) or future reproduction (survival)

530 "POL capture by life history trait encompassing trade-off between current and future reproduction. Trait is called "exploration". Higher exploration = lower current 531 reproduction but higher future reproduction, lower exploration = higher current reproduction but lower future reproduction. Other combinations of current/future 532 reproduction (e.g. high-high, low-low) are not possible 